BAOZHEN YAO ${ }^{1}$

E-mail: yaobaozhen@hotmail.com

QINGDA CAO ${ }^{1}$

E-mail: caoqd_dl@163.com

LU JIN ${ }^{1}$

E-mail: jinlu_dı@126.com

MINGHENG ZHANG ${ }^{1}$

E-mail: gloriazhang@163.com

YIBING ZHAO ${ }^{1}$

(Corresponding author)

E-mail: zhaoyibing@dlut.edu.cn

${ }^{1}$ School of Automotive Engineering,

Dalian University of Technology, Dalian, 116024, China
Traffic in the Cities

Preliminary Communication Submitted: 2 Dec. 2015

Accepted: 16 Nov. 2016

\title{
CIRCLE LINE OPTIMIZATION OF SHUTTLE BUS IN CENTRAL BUSINESS DISTRICT WITHOUT TRANSIT HUB
}

\begin{abstract}
The building density of Central Business District (CBD) is usually high. Land for a bus terminal is insufficient. In this situation, passengers in CBD have to walk far to take a bus, or take a long time to wait for a taxi. To solve this problem, this paper proposes an indirect approach: the design of a circle line of shuttle bus as a dynamic bus terminal in CBD. The shuttle bus can deliver people to the bus station through a circle line. This approach not only reduces the traffic pressure in $C B D$, but also saves travel time of the passenger. $A$ bi-objective model is proposed to design a circle line of a shuttle bus for CBD. The problem is solved by non-dominated sorting genetic algorithm (NSGA-II). Furthermore, the Dalian city in China has been chosen as the case study to test the proposed method. The results indicate that the method is effective for circle line optimization of shuttle bus in central business district without a bus terminal.
\end{abstract}

\section{KEY WORDS}

Central Business District; shuttle bus; transfer; genetic algorithm; bi-objective model;

\section{INTRODUCTION}

\subsection{Background}

Central Business District (CBD) is an important area of traffic attraction. With the development of a city, the traffic congestion has become a serious problem now and the conflict between traffic demand and traffic supply of traffic facilities has become increasingly prominent. During peak hours, the bus line and intersection congestion are common. For most cities, a bus terminal in CBD can improve the traffic condition. Because of the scarce and expensive land resources in CBD, many cities do not have bus terminals in CBD. Thus, it is feasible to design a circle line of a shuttle bus that makes use of the existing important bus stops. People can get to the bus stops by shuttle bus instead of walking. The shuttle bus has many outstanding features, such as short stop spacing, short interval, low fare and good service. The shuttle bus can achieve the functions of transfer as a dynamic bus terminal. Dynamic bus terminal indicates that a shuttle bus can pass through bus stations or bus terminals of different buses in CBD by a circle line. Moreover, a shuttle bus can deliver passengers to different bus stations or bus terminals which they want to reach in CBD.

The shuttle bus line design is introduced in this paper to solve the transfer in CBD, especially for the ones that lack land resources. The line can also provide convenient transfer services for passengers when the bus terminal is unavailable. The shuttle bus reduces the traffic congestion by lowering the car or taxi travel. Therefore, the optimization of the stop selection of a shuttle bus and the operation strategies proposed in this paper are of significance for the traffic congestion in CBDs.

\subsection{Literature review}

Some studies have focused on the circle rail transit. Warade [1] proposed a circle line in Chicago which would serve the urban core of the Chicago region, and was likely to significantly affect both land use and travel patterns. The paper developed the frameworks and models for the Circle Line project and applied it to quantify the accessibility and development impacts of the Circle Line project. Zhibin et al. [2] studied the circle rail transit line timetable scheduling, and they discussed the definition of circle line topology structure, time-space structure, and transfer schemes.

Due to the limited studies of circle line of shuttle bus, studies about transfer from bus to other modes of transport can be referenced in this paper. Chen et 
al. [3] proposed a spatiotemporal data model for time geographic entities, which include space-time path, station, prism, and lifeline, in road networks. Wirasinghe [4] presented an approximate analytical model of a rail plus feeder bus system. The system served a peak-period many-to-one type demand. Bookbinder and Desilets [5] minimized the overall inconvenience to passengers for transfer optimization. Martins and Pato [6] focused on establishing a model. A two-phase method was used to solve the feeder bus network design problem (FBDP). The objective was to minimize the cost function, where interests of both passenger and operator were considered. Quadrifoglio and Li [7] proposed an analytical model and solution to the problem, and verified the validity of the analytical modelling approach by comparing to the values generated from simulation. Proper design and operations are becoming increasingly important to enhance the performance of the public transportation system network. Ceder [8] designed an integrated smart feeder/shuttle service established to overcome the problem of using an excessive number of cars arriving and parking at the train station within the same time span. This work developed a new idea of an integrated and innovative feeder/shuttle system with new operating and routing concepts. Dikas and Minis [9] modelled a design problem by a mixed integer-linear program. Such a system may offer higher quality of transport to clients with disability without increasing significantly the public transport expenditure. Braekers et al. [10] presented a meta-heuristic algorithm which is an excellent and efficient tool for solving larger problems comparing to branch-and-cut algorithm. Lai et al. [11], Saka [12], Chien and Qin [13] focused on the optimization of bus stop location and spacing.

Large numbers of studies are available on problems related to feeder bus scheduling or departure frequency that is in accordance with the main transit. Shafahi and Khani [14] represented two models with the aim of minimizing the transfer waiting time in transit networks. Sivakumaran et al. [15] used continuum models to analyze cases in which the trunk-line vehicle schedule was given exogenously. In the model, coordination could be Pareto improving and operator and user costs both diminished, when the frequencies of trunk and feeder services could be established jointly. Sumalee et al. [16] proposed a multi-modal transport network assignment model considering uncertainties in both demand and supply of the network. Zhibin and Qixiang [17] arranged the service-based shuttle bus timetable in accordance with the rail transit. The model achieved a seamless connection from the rail transit station to the living community. Fu et al. [18] presented a reliability-based user equilibrium traffic assignment model for congested multi-modal transport networks under demand uncertainty. Liu et al. [19] studied transit users' route choice in the context of transit assignment in three groups: static transit assignment, within-day dynamic transit assignment, and emerging approaches. The bus frequency or bus scheduling for transfer can be found in literature [20-25].

Additionally, some studies have jointly considered the feeder bus network and scheduling. Shrivastava and O'Mahony [26] optimized the feeder routes and frequencies simultaneously using genetic algorithms. Martínez and Eiró [27] designed a minibus feeder service for the Sintra rail line. The formulation was divided into three main steps: the establishment of stops, scheduling and fleet dimensioning. Ibeas et al. [28] developed a bi-level optimization model for locating bus stops to minimize the social cost of the overall transport system. They took into account possible changes in demand due to different bus stop locations considering congestion on buses. They [29] also proposed an optimization model for designing the intervals (headways) and sizes of buses circulating on public transport networks by minimizing the system's operating and user costs. The proposed model takes into account congestion on the public transport system. Szeto and Wu [30] aimed to improve the existing bus services by reducing the number of transfers and users' total travel time. Ruisanchez and Ibeas [31] presented a bi-level optimization model to assign optimal bus sizes and frequencies to public transport routes. The upper level problem of the proposed model minimizes the cost function representing the costs of the users and operators, and the lower level solves a public transport assignment model subject to capacity constraint. An integrated solution method was proposed in which a genetic algorithm would tackle the route design problem and a neighbourhood search heuristics would deal with the frequency setting problem. Besides, Ngamchai and Lovell [32], Chen et al. [33], have also carried out similar studies.

\subsection{Contributions}

This paper presents a new idea about the shuttle bus through a circle line in CBD. An airport ferry bus can remove the passengers from the lounge to the far seat aircraft they want to go. Similar to the airport ferry bus, the shuttle bus would transfer people to the bus station which they want to reach through a circle line. Because of the high population density and the high degree of congestion in CBD, the design of a shuttle bus can reduce the degree of congestion and provide people with services of convenience. In the shuttle bus line design, there is a conflict of interest between the operator and the passenger. To make passengers more satisfied and the operator costs lower, the stop selection and headway should be weighted at the same time. Therefore, both bus stop selection and headway are important for a successful shuttle bus regular management. 
There are two main contributions in this paper. Firstly, a new idea about the shuttle bus as a dynamic bus terminal through a circle line in CBD is presented in this paper. Due to crowded population and expensive land in CBDs, it is very difficult to create a new bus terminal to facilitate passengers. So this paper presents an idea about a shuttle bus as a dynamic bus terminal to deliver people from different locations in CBD to the bus stations to which they want to go. Secondly, the passengers prefer high frequency to reduce their travel time while the bus operators try their best to reduce the operation cost. This paper builds a bi-objective model to balance the benefits of the passengers and the bus operator which improves the implementation probability of the optimal scheme. In addition, real data of Dalian city in China are used to test the optimization model.

The rest of the paper is organized as follows: Section 2 introduces the bi-objective model of shuttle bus line design for transfer; the NSGA II is described in Section 3; a case study of Dalian city, the convergence of the algorithm and the results analysis are presented in Section 4; and finally, the conclusions and directions for future research are presented in Section 5 .

\section{THE CIRCLE LINE OF SHUTTLE BUS OPTIMIZATION MODEL FOR TRANSFER}

\subsection{Problem description}

CBD is the meeting-place of pedestrian flows and traffic streams. For a CBD without bus terminals, passengers have to walk far to get to a bus stop. Passengers can also choose to take a taxi, but they have to wait for a long time and spend a lot of money. Lacking a bus terminal causes dissatisfaction of passengers and they lose preference for public transport facilities. However, after opening a shuttle bus, the situation will change. Figure 1 shows the change of the passenger flow in CBD after opening a circle line of shuttle bus. The shuttle bus runs quickly through the important bus stops which connect the bus routines in other directions. For example, passenger $A$ in Figure 1 a wants to go to the bus station A for taking bus A. From A's position to the bus station, taking a taxi would cost passenger $\mathrm{A}$ a lot and it is also inconvenient for people to take a taxi in CBD which is always congested. Thus, passenger $A$ has to walk a long distance to get to bus station $A$. There are plenty of people who have a similar situation as passenger $A$ in $C B D$, such as passenger B, C and grey people (shown in Figure 1a), etc. This situation increases the degree of congestion and generates chaos in CBD. The situation would be alleviated after opening a shuttle bus circle line (shown in Figure 1b). Passengers can take the shuttle bus at the shuttle bus stop which is close to them. The circle line will reduce the passengers' walking distance greatly and increase the convenience of passengers. The lack of a bus terminal in CBD can be solved by a shuttle bus transfer. It not only alleviates the traffic pressure, but it also reduces the travel time and costs of passengers.

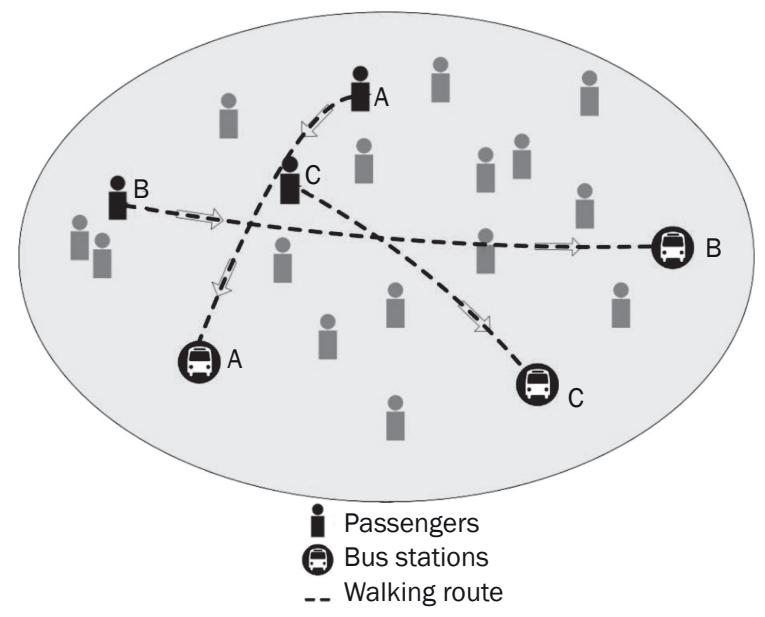

a) Passenger flow before opening the shuttle bus circle line

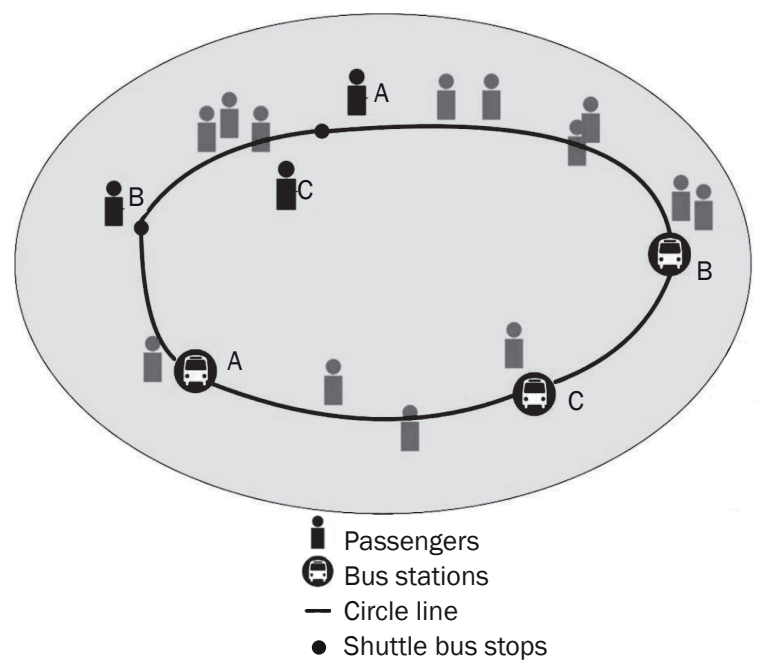

b) Passenger flow after opening the shuttle bus circle line

Figure 1 - The changes of passenger flows after opening the shuttle bus circle line

\subsection{Assumptions}

The following assumptions are introduced to simplify the building and calculation of the optimization model:

- When the shuttle bus departs from the bus stop, it accelerates uniformly to normal operating speed; when the shuttle bus reaches the bus stop, it decelerates the normal operating speed to rest uniformly; 
- All passengers near the bus stop of circle lines will walk to the bus stop;

- Passengers arriving at the bus stop submit to uniform distribution and the average waiting time is half the headway (the number of people in CBD is large, so the average was used for calculation);

- The first shuttle bus passengers encounter at the bus stop still has space, supposing the shuttle bus can carry 60 people.

\subsection{The shuttle bus line optimization model}

This model sets up multiple alternative stops near each demand point in CBD. Then the appropriate stops are selected as shuttle bus stops to form the circle line of the shuttle bus as shown in Figure 2. At the same time, the model optimizes the bus headway in order to achieve the requirements of both passengers and the operator. In this paper, the interests of both passengers and bus operators are balanced, corresponding to the minimum cost of passengers and the minimum cost of the operators, respectively. The cost of passengers is reflected on the total travel time, including the walking time from the origin to the bus stop, waiting time at the bus stop, time on the bus and walking time from the bus stop to the destination. The interest of the operator embodied in the operating costs, including the depreciation and maintenance cost of the bus stops and the cost of the fuel consumption and bus wear.

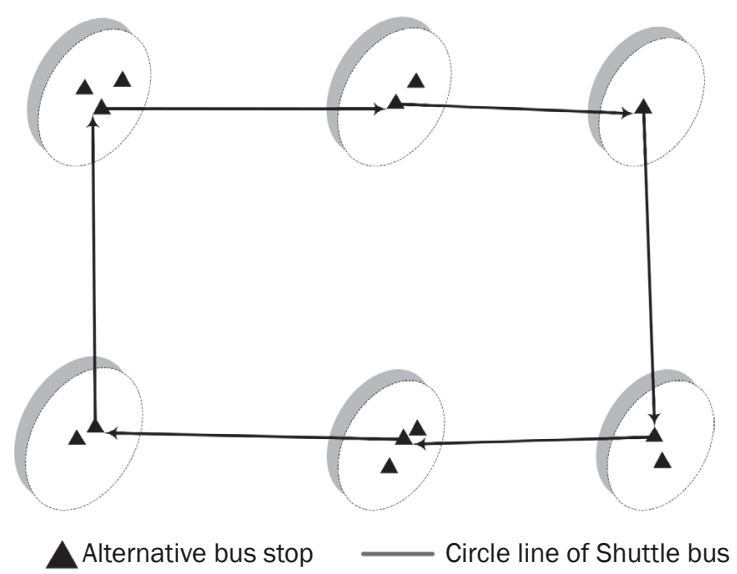

Figure 2 - Schematic diagram of shuttle bus line optimization model

\subsubsection{First objective: minimum passenger travel cost}

The first objective is to minimize the passenger travel cost, which includes the walking time cost from origin to bus stop, the waiting time cost at the bus stop, the time cost on the bus and walking time cost from the bus stop to the destination. The specific formulas are shown as follows:

$\operatorname{Min} P C_{1}+P C_{2}+P C_{3}+P C_{4}$
- Walking time cost from origin to bus stop and walking time cost from bus stop to destination

$P C_{1}=\eta \cdot \sum_{i=1}^{n} \frac{l_{i}}{V} \cdot O_{i} \cdot x_{i}$
$P C_{2}=\eta \cdot \sum_{i=1}^{n} \frac{l_{i}}{v} \cdot D_{i} \cdot x_{i}$

where $P C_{1}$ is the walking time cost from origin to bus stop; $P C_{2}$ is the walking time cost from bus stop to destination; $n$ is the set of bus stops; $\eta$ represents the value of unit time; $O_{i}$ is the trip generation at bus stop $i ; D_{i}$ is the trip attraction at bus stop $i ; l_{i}$ is passenger's walking distance to bus stop $i ; v$ is the passenger walking speed; $x_{i}$ is $0-1$ variable; if the alternative bus stop is chosen, the value of $x_{i}$ is 1 , otherwise it is 0 .

- Waiting time cost at bus stop and time cost on the bus

$$
\begin{aligned}
P C_{3}= & \eta \cdot \sum_{i=1}^{n}\left(O_{i} \cdot \frac{H}{2}+\lambda_{1} \cdot n_{i}\right) \cdot x_{i} \\
P C_{4}= & \eta \cdot \sum_{i=1}^{n} \sum_{j=1}^{n}\left(\theta_{i j} \cdot\left(\frac{l_{i j} \cdot x_{i} \cdot x_{j}}{u}-\frac{u b+3 u a}{2 a b}\right) .\right. \\
& \left.\cdot\left(\sum_{k=1}^{i} O_{k}-\sum_{m=2}^{i} D_{m}\right)\right)
\end{aligned}
$$

where $P C_{3}$ is the waiting time cost at the bus stop; $P_{4}$ is the time cost on the shuttle bus; $H$ is the headway; $\lambda_{1}$ represents the time of one passenger getting on or off a bus; $n_{i}$ represents the max number of people getting on or off the bus at bus stop $i ; \theta_{i j}$ is $0-1$ variable; if $i$ and $j$ are two adjacent bus stops, the value of $\theta_{i j}$ is 1 , otherwise 0 . $I_{i j}$ is the length of arcs $i, j ; u, a, b$ represent normal speed, acceleration and deceleration, respectively; $\frac{l_{i j} \cdot x_{i} \cdot x_{j}}{u}-\frac{u b+3 u a}{2 a b}$ is the time on shuttle bus from stop $i$ to $j$, consisting of acceleration time, running time at normal speed and deceleration time; $\sum_{k=1}^{i} O_{k}-\sum_{m=2}^{i} D_{m}$ is the passenger trip flow between stops $i$ and $j$.

\subsubsection{Second objective: minimum operating cost of operator}

The second objective is to minimize the operating cost of the operator, which includes depreciation and maintenance cost of bus stops, cost of fuel consumption and bus wear, fixed costs of the circle line. The specific formulas are shown as follows:

$\operatorname{Min} O C_{1}+O C_{2}+O C_{3}$

- Depreciation and maintenance cost

$O C_{1}=\sum_{i=1}^{n} x_{i} \cdot \lambda_{2}$ 
where $O C_{1}$ is depreciation and maintenance cost of bus stops; $\lambda_{2}$ represents the daily maintenance and depreciation expenses of each bus stop.

- Cost of fuel consumption and bus wear

$$
\begin{aligned}
\mathrm{OC}_{2}= & \sum_{i=1}^{n} \sum_{j=1}^{n} \frac{T}{H} \cdot \theta_{i j}\left[\lambda_{3} \cdot\left(\frac{l_{i j} \cdot x_{i} \cdot x_{j}}{u}-\left(\frac{u}{2 a}+\frac{u}{2 b}\right)\right)+\right. \\
& \left.+\lambda_{4}\left(\frac{u}{a}+\frac{u}{b}\right)+\sum_{i=1}^{n} \lambda_{5} \cdot n_{i}\right]
\end{aligned}
$$

where $O C_{2}$ is the cost of fuel consumption and shuttle bus wear; $T$ is bus operating time; $\frac{T}{H}$ are the running times of buses in $T$ hours a day; $\lambda_{3}$ represents the average fuel consumption and loss per unit time under normal speed; $\lambda_{4}$ represents the average fuel consumption and loss per unit time when accelerating or decelerating; $\lambda_{5}$ represents the average fuel consumption and loss when each person gets on or off the bus; $n_{i}$ represents the max number of people getting on or off the bus at bus stop $i$.

- Fixed costs of the circle line

$O C_{3}=\frac{L}{\bar{u} \cdot H}\left(\lambda_{6}+\lambda_{7}\right)$

where $\mathrm{OC}_{3}$ are fixed costs of the circle line; $L$ is the total length of shuttle bus regular management; $\bar{u}$ is the average speed of a bus in a shuttle bus routine; $\frac{L}{\bar{u} \cdot H}$ is the total number of shuttle buses; $\lambda_{6}$ represents the depreciable cost of a shuttle bus one day; $\lambda_{7}$ represents the stuff cost of a shuttle bus one day.

\subsubsection{Constraints}

In this paper, the shuttle bus stop spacing, headway, total length of line and ensuring circle line are restricted. The specific formulas are shown as follows:

$$
\begin{aligned}
& I_{\min } \leq I_{i j} \cdot \theta_{i j} \cdot x_{i} \cdot x_{j} \leq I_{\max } \\
& H_{\min } \leq H \leq H_{\max } \\
& I_{i} \cdot x_{i} \leq D_{w} \\
& L_{\min } \leq \sum_{i=1}^{n} \sum_{j=1}^{n} I_{i j} \cdot \theta_{i j} \cdot x_{i} \cdot x_{j} \leq L_{\max } \\
& \sum_{i=1}^{n} \delta_{k i} \cdot x_{i}=1 \\
& \sum_{j=1}^{n} \theta_{i j}=\sum_{k=1}^{n} \theta_{k i}, \forall i \\
& \sum_{i=1}^{n} x_{i}=\sum_{i=1}^{n} \sum_{j=1}^{n} \theta_{i j}, \forall i
\end{aligned}
$$

where, $I_{\min }$ and $I_{\max }$ are the shortest and longest bus spacing; $H_{\max }, H_{\min }$ represent the upper and lower bound of headway; $L_{\min }$ and $L_{\max }$ are the shortest and longest total length of shuttle bus regular management; $D_{w}$ is the maximum tolerance of passengers walking distance; $\delta_{k i}$ is a 0-1 variable; if stop $i$ is within the demand point $k$, the value of $\delta_{k i}$ is 1 , otherwise it is 0 .

Constraint 9 restricts the bus stop spacing; Constraint 10 restricts the bus headway; Constraint 11 indicates that passenger walking distance cannot exceed the maximum tolerance; Constraint 12 stands for the range of the total line length; Constraint 13 represents that only one stop is the selection for one demand point. Constraints 14 and 15 ensure the shuttle bus regular management to be a circle line: The left side of Equation 15 represents the total number of bus stops. The right side represents the total number of road links in a circle line. In addition, $x_{i}$ and $H$ are the decision variables in this paper.

\section{ELITIST NON-DOMINATED SORTING GENETIC ALGORITHM}

A large part of literature suggested that heuristic algorithm was often the first choice to solve this kind of complicated problems. To optimize the circle line of a shuttle bus and its corresponding headway, a heuristic algorithm, Elitist Non-dominated Sorting Genetic Algorithm (NSGA- II), F was introduced. The non-dominated sorting GA (NSGA) was proposed by Srinivasan and Deb [34]. Then, Deb et al. [35] improved it to be NSGAII which had been applied to various problems. Shimamoto et al. [36] proposed a method for evaluating the effect of transit fare systems on passengers' behaviour. Both total cost and connection reliability were adopted as the evaluation index of the problem. NSGAII was used to solve this problem. Kwan and Chang [37] improved NSGA- II for timetable synchronization. Lau et al. [38] used NSGA- II to solve the transportation problem. Song et al. [39] suggested a multi-objective model to plan the regional bus timetable. The Elitist Non-Dominated Sorted Genetic Algorithm- II was employed to search a group of Pareto optimal solutions for the model. Khoo et al. [40] solved the problems of selection and scheduling of the exclusive bus lane with NSGA-II. Compared with NSGA, NSGA-II could reduce the complexity. NSGA-II can also increase the diversity and avoid the algorithm prematurely converging to local optimal, and the algorithm mutates the superposition individuals in the objective space and adds some new individuals to every generation.

\subsection{Fast non-dominated sorting approach}

As there is conflict of interests between passengers and the operator, we need to strike a balance between the two goals made. NSGA II is used in this paper. The main features of NSGA II are low computational requirements, elitist approach, and parameter-less 
sharing approach. For each solution two entities should be calculated: $n_{i}$ is the number of solutions which dominate solution $i$, and $S_{i}$ is a set of solutions in which solution $i$ dominates. First, we identify all those points which have $n_{i}=0$ and put them in a list $F_{1}$ called the current front. Second, for each solution in the current front we visit each member (j) in its set $S_{i}$ and reduce its $n_{j}$ count by one. By doing so, for any member $j$ if the count becomes zero, it is put in a separate list $H$. When all members of the current front have been checked, the members in the list $F_{1}$ are declared as members of the first front. Then we continue this process using the newly identified front $H$ as our current front. This process continues till all fronts have been identified. The overall complexity of the algorithm is $O\left(m N^{2}\right) . N$ is the size of population; $m$ is the number of objectives.

\subsection{Density estimation}

To get an estimate of the density of solutions surrounding a particular point in the population, we take the average distance between the two points on either side of this point along each of the objectives. This quantity $i_{\text {distance }}$ serves as an estimate of the size of the largest cuboid enclosing point $i$ without including any other point in the population called crowding distance. In Figure 3, the crowding distance of the $i$-th solution in its front (marked with solid circles) is the average sidelength of the cuboid (shown with a dashed box).

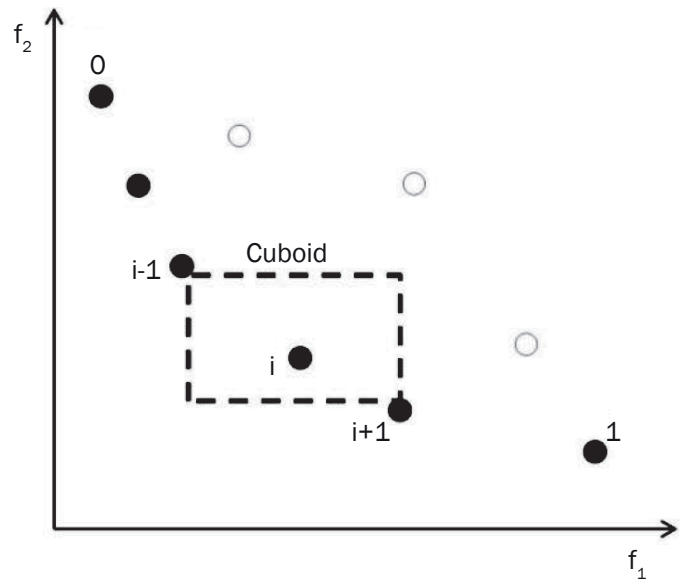

Figure 3 - The crowding distance calculation

\subsection{Crowded comparison operator}

The crowded comparison operator $(>n)$ guides the selection process at various stages of the algorithm towards a uniformly spread-out Pareto-optimal front. Assume that each individual in the population has two attributes: (1) Non-domination rank $\left(i_{\text {rank }}\right)$ and (2) Local crowding distance $\left(i_{\text {distance }}\right)$.

Define a partial order $\geq n$ as: $i>n_{j}$, if $\left(i_{\text {rank }}<j_{\text {rank }}\right)$ or $\left(i_{\text {rank }}=j_{\text {rank }}\right)$ and $\left(i_{\text {distance }}>j_{\text {distance }}\right)$. That is to say that if non-dominated sorting of two individuals is different, the one with smaller sorting number is taken; if the two individuals are at the same level, the less crowded one is taken.

\subsection{Coding}

In this paper, real number coding is used. Each coding is on behalf of a stop or headway of the shuttle. Specific process is as follows: demand point, alternative stops of each demand point and headway range should be made sure first. Then, it is supposed that $P$ is the number of demand points and $Q$ is the number of alternative bus stops in CBD. The coding length of each chromosome is $Q+1$. The last one is a representative of the headway.

\subsection{The process of algorithm}

The flow chart of the optimization for the bi-objective model is shown in Figure 4. And the concrete steps of the NSGA-II algorithm in this paper are as follows:

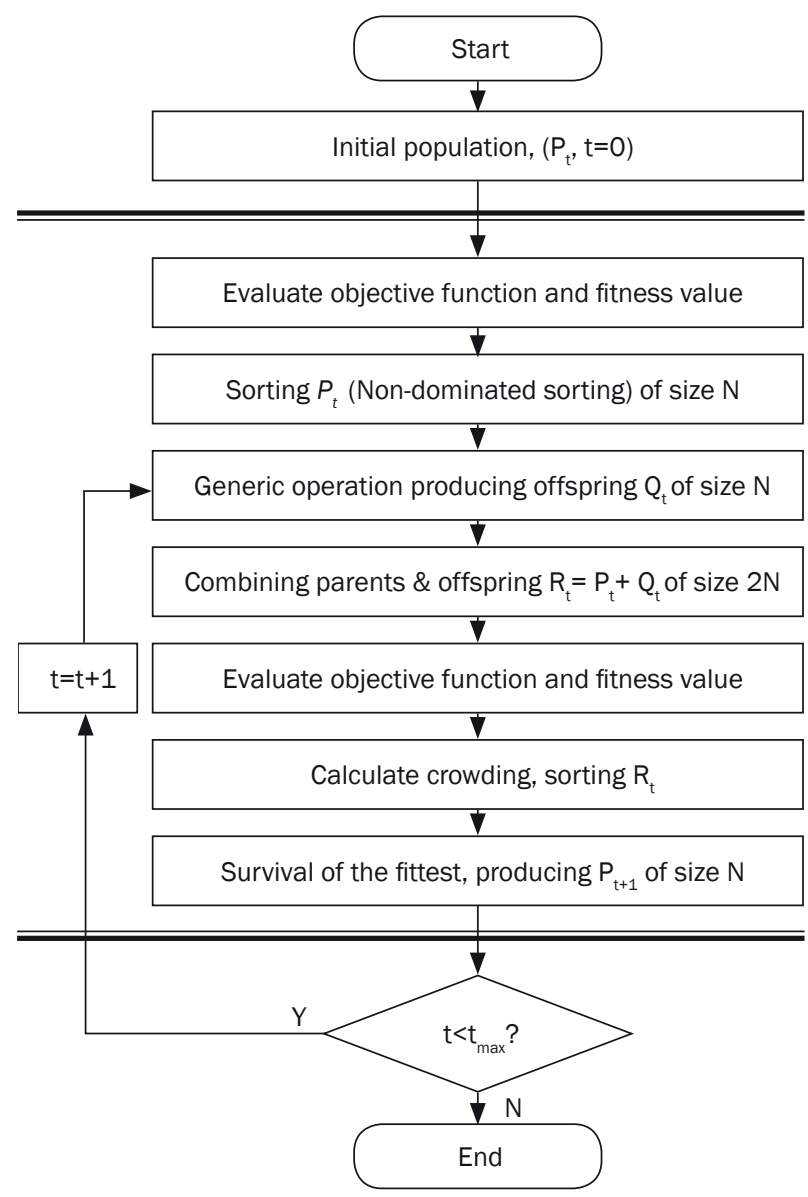

Figure 4 - Flow chart of NSGA-Il optimization procedure in this work

Step 1: Generating an initial population of chromosomes. A random parent population $P_{0}$ of size $N$ is created. Evaluating the objective function and the 
fitness value. (Min $P_{1}+P C_{2}+P C_{3}+P C_{4}$ and Min $O_{1}+$ $\left.O C_{2}+O C_{3}\right)$. The population is sorted based on the non-domination. Each solution is assigned a fitness equal to its non-domination level ( 1 is the best level).

Step 2: Binary tournament selection, recombination, and mutation operators are used to create a child population produce an offspring $Q_{0}$ of size $N$.

Step 3: Performing the elite strategy of NSGA-II. A combined population $R_{t}=P_{t}+Q_{t}$ is formed. The population $R_{t}$ will be of size $2 N$. The population $R_{t}$ is sorted according to non-domination. Then, the crowding distance in the current front is calculated, producing population $P_{t+1}$ based on crowding distance comparison.

Step 4: Judging whether to continue calculation or not. If iteration reaches maximum times then terminate calculation and output the maximum fitness; otherwise, return to Step 2 to continue the calculation.

\section{CASE STUDY}

\subsection{Essential data}

In this paper, about 5 square kilometres of area around the Dalian Railway Station were taken as the research object. This region covers the Dalian Railway Station, Qingniwa Bridge CBD and many hotels and shopping centres. It is the most prosperous area in Dalian. According to actual road network and land use, the research object is divided into 11 demand points ( $A$ - K), including 30 alternate stops as shown in Figure 5. The demand points are the bus stations which the passengers want to reach most. The CBD is divided into traffic zones. The demand points are obtained through the investigation based on the actual location of bus stations and passengers' travelling needs in CBD. Several alternate stops are chosen for each demand point separately, and the best points of the alternate stops are chosen as the final demand points.

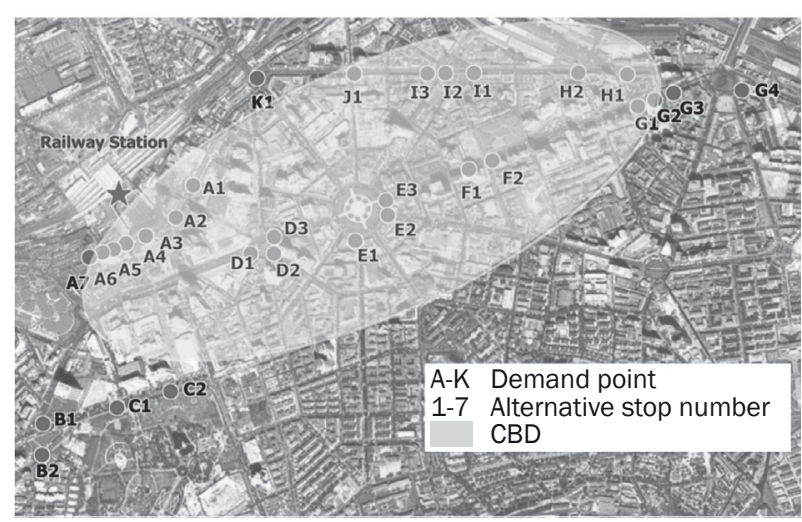

Figure 5 - Distribution of alternative bus stops

The case is based on the public transportation system planning. The basic data are obtained by typical traffic surveys on the bus. The traffic survey was conducted during April 8-10, 2013. It is observed that most passengers travel during 7-9 a.m. and 5-7 p.m. Therefore, the two time periods are identified as the peak hours. In addition, it assumes that the operating time $(T)$ of shuttle bus is sixteen hours. There are four hours of peak time and twelve hours of off-peak time. Due to the higher passenger trip flow per hour at the peak time, different headways corresponding to the peak time and off-peak time are optimized. The numbers of passengers getting on and off at bus stops are shown in Table 1 and Table 2, respectively. Then the passenger trip flows on the road segment can be calculated. The purpose of establishing this circle line is to make the trips of people who want to go to the bus stops nearby more convenient. So there is no need to establish new bus stops for the circle line. One just chooses the already existing points in the CBD, and make them be a circle line.

More than one parameter is involved in this paper, so the specific values will be determined on the base of the specification of the urban traffic planning, as shown in Table 3.

\subsection{The results of the circle line of shuttle bus optimization}

Table 1 - The numbers of passengers getting on and off at bus stop during the peak hours of a day (person/day)

\begin{tabular}{|c|c|c|c|c|c|c|c|c|c|c|c||}
\hline & A & B & C & D & E & F & G & H & I & J & K \\
\hline \hline ON & 2,570 & 802 & 1,012 & 884 & 739 & 945 & 713 & 307 & 1,708 & 151 & 222 \\
\hline OFF & 2,554 & 250 & 865 & 1,312 & 1,115 & 832 & 1,335 & 267 & 1,062 & 301 & 160 \\
\hline
\end{tabular}

Table 2 - The numbers of passengers getting on and off at bus stop during the off-peak hours of a day (person/day)

\begin{tabular}{|c|c|c|c|c|c|c|c|c|c|c|c||}
\hline & A & B & C & D & E & F & G & H & I & J & K \\
\hline \hline ON & 4,570 & 1,426 & 1,800 & 1,572 & 1,313 & 1,679 & 1,267 & 545 & 3,036 & 269 & 394 \\
\hline OFF & 4,540 & 444 & 1,537 & 2,332 & 1,982 & 1,480 & 2,373 & 474 & 1,889 & 535 & 285 \\
\hline
\end{tabular}


B. Yao, Q. Cao, L. Jin, M. Zhang, Y. Zhao: Circle Line Optimization of Shuttle Bus in Central Business District without Transit Hub

Table 3 - Parameter and value of the model

\begin{tabular}{||c|l|c||}
\hline \hline Parameter & \multicolumn{1}{|c|}{ Parameter specification } & Value \\
\hline \hline$\eta$ & the value of unit time [yuan/h] & 15 \\
\hline$u$ & normal speed [m/s] & 12 \\
\hline$a$ & acceleration [m/s $\left.{ }^{2}\right]$ & 0.6 \\
\hline$b$ & deceleration [m/s $\left.{ }^{2}\right]$ & 2 \\
\hline$H_{\min }$ & lower bound of headway [min] & 1 \\
\hline$H_{\max }$ & upper bound of headway [min] & 10 \\
\hline$D_{w}$ & the maximum tolerance of walking distance [m] & 100 \\
\hline$V$ & the passenger walking speed [km/h] & 5 \\
\hline$T_{p}$ & the peak hour [h] & 4 \\
\hline$T_{0}$ & the off-peak hour [h] & 12 \\
\hline$\lambda_{1}$ & the time of one passenger get on or off a bus at bus stop [min] & 0.1 \\
\hline$\lambda_{2}$ & daily maintenance and depreciation expense of each bus stop [yuan/day] & 20 \\
\hline$\lambda_{3}$ & average fuel consumption and loss per unit time under normal speed [yuan/s] & 0.08 \\
\hline$\lambda_{4}$ & average fuel consumption and loss per unit time when accelerating or decelerating [yuan/s] & 0.12 \\
\hline$\lambda_{5}$ & average fuel consumption and loss when each person get on or off the bus [yuan] & 1 \\
\hline$\lambda_{6}$ & the depreciable cost of a shuttle bus one day [yuan/day] & 135 \\
\hline$\lambda_{7}$ & the stuff cost of a shuttle bus one day [yuan/day] & 165 \\
\hline
\end{tabular}

\subsubsection{Calculation results}

NSGA- II algorithm is applied in this paper to solve the bi-objective model. The optimized minimum cost is RMB 105,120 during the operating hours. The minimum cost of peak hours is RMB 35,403 , while it is RMB 69,717 during off-peak times as shown in Table 4. The actual passenger cost (without taking a shuttle bus), including passengers' walking time cost or taxi fares from origin to destination is also shown in Table 4. Compared with the actual passenger cost, taking a shuttle bus can decrease the cost of passengers. The optimal result of bus stop selection is shown in Table 5 .

\section{Table 4 - Cost breakdown category}

\begin{tabular}{|c|c|c|c|c||}
\hline \hline & $\begin{array}{c}\text { Passenger } \\
\text { cost }\end{array}$ & $\begin{array}{c}\text { Operator } \\
\text { cost }\end{array}$ & Total cost & $\begin{array}{c}\text { Actual } \\
\text { passenger } \\
\text { cost }\end{array}$ \\
\hline \hline Peak & 26,430 & 8,973 & 35,403 & 47,210 \\
\hline Off-peak & 51,717 & 18,000 & 69,717 & 90,842 \\
\hline Total cost & 78,147 & 26,973 & 105,120 & 138,052 \\
\hline
\end{tabular}

There are seven alternative stops near the Dalian Railway Station and the fourth alternative stop is chosen. From the location of the fourth alternative stop, it can be seen that the alternative stop selection should not only consider the passengers' travel distance, but also the length of the road segment. If the length is too long, it will not be convenient for passengers to take a bus. If the length is too short, it will increase fuel consumption. There are four alternative stops near the

Table 5 - Selection plan of alternative bus stops

\begin{tabular}{|c|c|c|c|c|c||}
\hline Sequence number & Selected or not & Sequence number & Selected or not & Sequence number & Selected or not \\
\hline \hline A1 & 0 & C2 & 1 & G2 & 0 \\
\hline A2 & 0 & D1 & 0 & G3 & 1 \\
\hline A3 & 0 & D2 & 1 & G4 & 0 \\
\hline A4 & 1 & D3 & 0 & H1 & 0 \\
\hline A5 & 0 & E1 & 0 & H2 & 1 \\
\hline A6 & 0 & E2 & 1 & I1 & 1 \\
\hline A7 & 0 & E3 & 0 & I2 & 0 \\
\hline B1 & 1 & F1 & 0 & I3 & 0 \\
\hline B2 & 0 & F2 & 1 & J1 & 1 \\
\hline C1 & 0 & K1 & & 1 \\
\hline
\end{tabular}

Note: 1 - selected, 0 - not selected 
Harbour Square, and one of the four alternative stops is on the square. The optimization result is to choose the third alternative stop close to the square. This is convenient for passengers to get on or off the shuttle bus and shorten the walking distance. Meanwhile, the shuttle bus does not need to stop in the square and the running speed is relatively uniform.

Headway is another important decision variable in this paper. The optimization results of peak hours and off-peak hours are $5.03 \mathrm{~min}$ and $8.45 \mathrm{~min}$, respectively. The shuttle bus circle line should be convenient for passengers to transfer to other bus routes or other modes of transport. So the headway of the shuttle bus cannot be too long. On the other hand, a short headway means the operator has to invest more vehicles. Both fixed cost and variable cost will increase. Considering the demand of transport during the peak time and the off-peak time, the optimization of headway in this paper conforms to the requirements of the interests of passengers and operators. During peak hours, short headway makes the waiting time moderate; during off-peak time, a long headway guarantees that the capacity is not wasted and the cost of operators does not increase much.

After selecting the bus stops, the circle line of the shuttle bus is formed according to the situation on the road and the land use. The shuttle bus runs through Dalian Railway station, Hope Square, Labour Park, Youhao Square, Zhongshan Square, Renmin Road, Bay Bridge, Worker Street, Minsheng Street and Shengli Bridge as shown in Figure 6. The total line length of the shuttle bus is $8.08 \mathrm{~km}$. The cycle time of the shuttle bus in the peak hour is about $34 \mathrm{~min}$. The cycle time of the shuttle bus in the off-peak hour is about $17 \mathrm{~min}$. And there will be seven buses on the line. The shuttle bus can quickly evacuate passengers gathering on the station square to other bus terminals. It is convenient for passengers to transfer to other modes of transport, and at the same time the phenomenon of waiting long for a taxi is alleviated effectively.

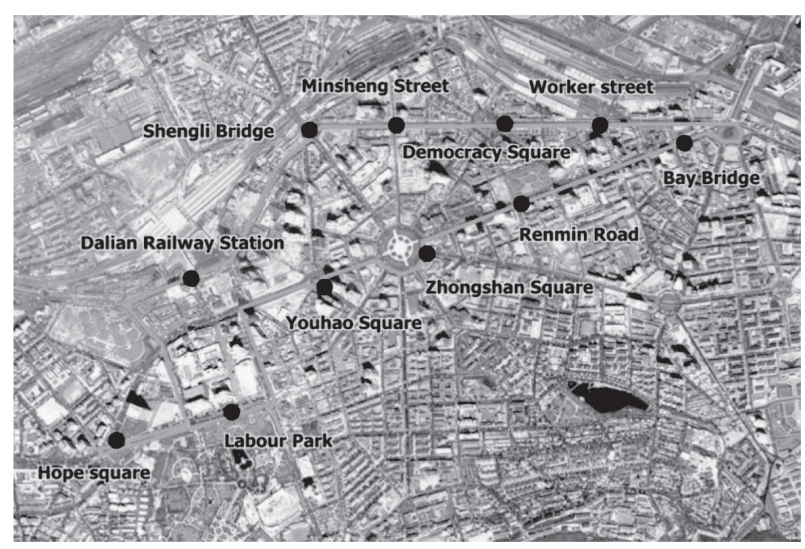

Figure 6 - The shuttle bus circle line

\subsubsection{Convergence of the algorithm}

In this paper, the crossover rate of NSGA- II is 0.95 and the mutation probability is 0.05 . The individual number of initial population is 100 . The algorithm evolves 100 iterations. The program runs 10 times to test the convergence of NSGA- II. The Pareto distribution is shown in Figure 7. Pareto solutions are approximate, so the optimal solution is obtained on the principle of minimizing the total cost.

In the initial stage of iteration, the proportion of non-dominated solution is on the rise. Even though in the sixth iteration there comes to a solution degradation, the convergence of the solution is not affected. After 20 iterations, all individuals in each generation are the non-dominated solution (Figure 8). It proves that the algorithm is convergent and reliable.

Finally, the NSGA-II is tested 10 times as shown in Figure 9. The total cost of NSGA-II is stable. Therefore, the proposed NSGA-II can improve the optimizing quality, and the algorithm has a good performance.

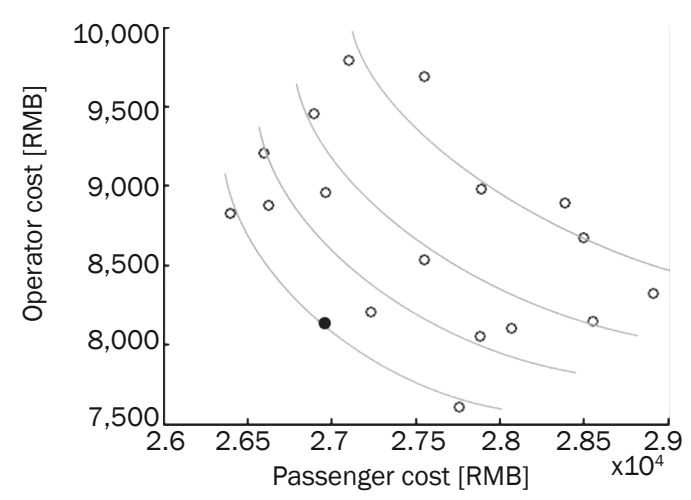

a) At peak time

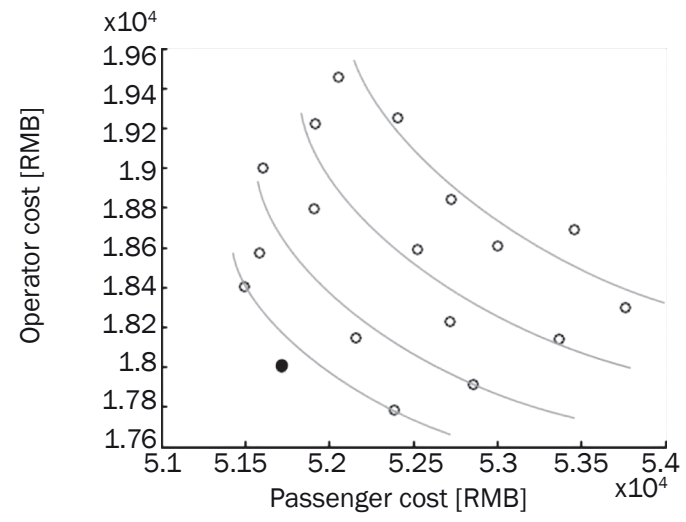

b) At off-peak time

Figure 7 - Pareto distribution 


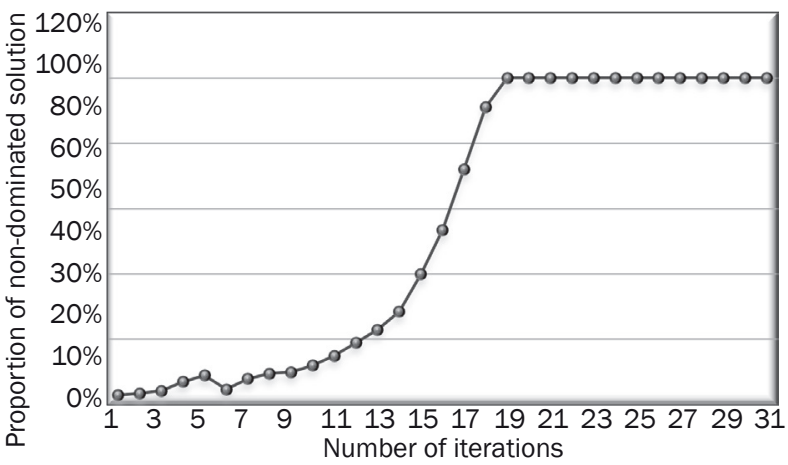

Figure 8 - Proportion of non-dominated solution in each iteration

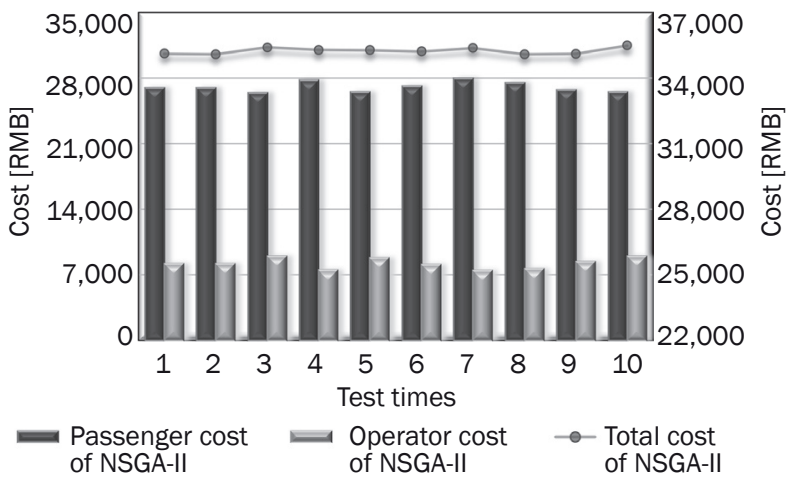

Figure 9 - Test of NSGA- II

\section{CONCLUSION}

To achieve the goal of relieving traffic congestion and improve the utilization of bus stops in CBD, this paper proposes a design of a circle line of a shuttle bus optimization model for transfer. The model is a bi-objective one. The objectives of this model are minimum passenger travel cost and minimum operator's cost. The interests of both passengers and the operator are taken into account. This paper takes about 5 square kilometres area around Dalian Railway Station as the research object to test the model. And NSGA-II is designed to solve the bus stop selection and determine the headway. The results of the case study show that the model has reliability and validity which can help the operator to make decisions and alleviate traffic pressure in CBD effectively.

For further studies, a new bus stop location and one-way street should be taken into account. The problem will be more complex. Thereby the practicability of the circle line of a shuttle bus can be improved accordingly.

\section{ACKNOWLEDGEMENTS}

This work was supported by the National Natural Science Foundation of China 51578112 and 71571026, National Basic Research Program of China
2012CB725401, the Trans-Century Training Program Foundation for Talents from the Ministry of Education of China NCET-12-0752 and the Fundamental Research Funds for the Central Universities 3132015062 and DUT16YQ104.

姚宝珍, 曹庆达, 金璐, 张明恒, 赵一兵 大连理工大学汽车工程学院

\section{无公交枢纽背景下中心商业区穿梭巴士环线优化}

摘要：中心商务区 ( $C B D)$ 的建筑密度通常较大, 没 有充足的空间建设公交枢纽。在这种情况下，位于 中心商务区的乘客必须走很远才能乘坐公共汽车, 或者 $=$ 花费很长的时间等待出租车。为了解决这个问 题, 本文提出了一种间接的解决方案: 在中心商务 区设计 $=$ 一条穿梭巴士环线作为动态公交枢纽站。穿 梭巴士通过环形路线将乘客疏散到各个公交车站,

这种方式不仅降低了中心商务区的交通压力, 而且 节省了乘客的出行时间。本文建立了一个双目标优 化模型以设计中心商务区的穿梭巴士环线, 并且运 用非支配排序遗传算法 (NSGA-II) 来求解。本文选 择中国大连市作为研究案例来检验该优化方法。结 果表明, 对于没有公交枢纽的中心商务区来说, 穿 梭巴士环线的开通可以解决中心商业区拥堵问题， 并发挥良好的公交枢纽的作用。

关键词:

中心商务区; 穿梭巴士 ; 换乘; 遗传算法; 双目标

\section{REFERENCES}

[1] Warade RK. The accessibility and development impacts of new transit infrastructure: the circle line in Chicago. Massachusetts Institute of Technology; 2007.

[2] Zhibin J, Jia G, Ruihua X. Circle rail transit line timetable scheduling using Rail TPM. WIT Transactions on The Built Environment. 2010;114:945-952.

[3] Chen B Y, Yuan H, Li Q, et al. Spatiotemporal data model for network time geographic analysis in the era of big data. International Journal of Geographical Information Science. 2016;30(6):1041-1071.

[4] Wirasinghe SC. Nearly optimal parameters for a rail/ feeder-bus system on a rectangular grid. Transportation Research Part A: General. 1980;14(1):33-40.

[5] Bookbinder JH, Desilets A. Transfer optimization in a transit network. Transportation science. 1992;26(2):106-118.

[6] Martins CL, Pato MV. Search strategies for the feeder bus network design problem. European Journal of Operational Research. 1998;106(2):425-440.

[7] Quadrifoglio L, Li X. A methodology to derive the critical demand density for designing and operating feeder transit services. Transportation Research Part B: Methodological. 2009;43(10):922-935.

[8] Ceder AA. Integrated smart feeder/shuttle transit service: simulation of new routing strategies. Journal of Advanced Transportation. 2013;47(6):595-618. 
[9] Dikas G, Minis I. Scheduled paratransit transport systems. Transportation Research Part B: Methodological. 2014;67:18-34.

[10] Braekers K, Caris A, Janssens G K. Exact and meta-heuristic approach for a general heterogeneous dial-a-ride problem with multiple depots. Transportation Research Part B: Methodological. 2014;67:166-186.

[11] Lai X, Li J, Li Z. A Subpath-based Logit Model to Capture the Correlation of Routes. Promet - Traffic \& Transportation. 2016;28(3):225-234.

[12] Saka AA. Model for Determining Optimum Bus-Stop Spacing in Urban Areas. Journal of Transportation Engineering. 2001;127(3):195-199.

[13] Chien SI, Qin Z. Optimization of bus stop locations for improving transit accessibility. Transportation planning and Technology. 2004;27(3):211-227.

[14] Shafahi Y, Khani A. A practical model for transfer optimization in a transit network: Model formulations and solutions. Transportation Research Part A: Policy and Practice. 2010;44(6):377-389.

[15] Sivakumaran K, Li Y, Cassidy M J, et al. Cost-saving properties of schedule coordination in a simple trunkand-feeder transit system. Transportation Research Part A: Policy and Practice. 2012;46(1):131-139.

[16] Sumalee A, Uchida K, Lam WHK. Stochastic multi-modal transport network under demand uncertainties and adverse weather condition. Transportation Research Part C: Emerging Technologies. 2011;19(2):338-350.

[17] hibin J, Qixiang H. A Service-based Method to Generate Shuttle Bus Timetable in Accordance with Rail Transit Timetable. Procedia-Social and Behavioral Sciences. 2013;96:1890-1897.

[18] Fu X, Lam WHK, Chen BY. A reliability-based traffic assignment model for multi-modal transport network under demand uncertainty. Journal of Advanced Transportation. 2014;48(1):66-85.

[19] Liu Y, Bunker J, Ferreira L. Transit Users' Route-Choice Modelling in Transit Assignment: A Review. Transport Reviews. 2010;30(6):753-769.

[20] Ceder A. Optimal design of transit short-turn trips. Transportation Research Record. 1989;(1221):9-22.

[21] Cepeda M, Cominetti R, Florian M. A frequency-based assignment model for congested transit networks with strict capacity constraints: characterization and computation of equilibria. Transportation research part B: Methodological. 2006;40(6):437-459.

[22] İnanlı A, Ünsal B, Türsel Eliiyi D. Route Optimization for the Distribution Network of a Confectionary Chain. Promet - Traffic \& Transportation. 2015;27(6):497-503.

[23] Yu B, Kong L, Sun Y, Yao BZ, Gao ZY. A bi-level programming for bus lane network design. Transportation Research Part C: Emerging Technologies. 2015;55:310327.

[24] Yu B, Peng Z, Wang K, et al. An optimization method for planning the lines and the operational strategies of waterbuses: the case of Zhoushan city. Operational Research. 2015;15(1):25-49.

[25] Yao BZ, Chen C, Cao QD, Jin L, Zhang MH, Zhu HB, Yu B. Short-term traffic speed prediction for an urban corridor. Computer-Aided Civil and Infrastructure Engineering. 2017:32(2):154-169.

[26] Shrivastava P, O'Mahony M. A model for development of optimized feeder routes and coordinated
schedules-A genetic algorithms approach. Transport policy. 2006;13(5):413-425.

[27] Martínez LM, Eiró T. An optimization procedure to design a minibus feeder service: an application to the sintra rail line. Procedia-Social and Behavioral Sciences. 2012;54:525-536.

[28] Ibeas Á, dell'Olio L, Alonso B, et al. Optimizing bus stop spacing in urban areas. Transportation research part E: Logistics and Transportation Review. 2010;46(3):446458.

[29] Ibeas A, Alonso B, dell'Olio L, et al. Bus Size and Headways Optimization Model Considering Elastic Demand. Journal of Transportation Engineering. 2013;140(4):04013021.

[30] Szeto WY, Wu Y. A simultaneous bus route design and frequency setting problem for Tin Shui Wai, Hong Kong. European Journal of Operational Research. 2011;209(2):141-155.

[31] Ruisanchez F, Ibeas A. Design of a tabu search algorithm for assigning optimal bus sizes and frequencies in urban transport services. Journal of Advanced Transportation. 2012;46(4):366-377.

[32] Ngamchai S, Lovell DJ. Optimal time transfer in bus transit route network design using a genetic algorithm. Journal of Transportation Engineering. 2003;129(5):510-521.

[33] Chen BY, Lam WHK, Sumalee A, et al. Reliable shortest path finding in stochastic networks with spatial correlated link travel times. International Journal of Geographical Information Science. 2012;26(2):365-386.

[34] Srinivas N, Deb K. Muiltiobjective optimization using nondominated sorting in genetic algorithms. Evolutionary computation. 1994;2(3):221-248.

[35] Deb K, Agrawal S, Pratap A, et al. A fast elitist non-dominated sorting genetic algorithm for multi-objective optimization: NSGA-II. Proceedings of the 6th International Conference on Parallel Problem Solving from Nature - PPSN VI; 2000 Sep 18-20; Paris, France. Berlin, Heidelberg: Springer; 2000. p. 849-858.

[36] Shimamoto $\mathrm{H}$, Kurauchi F, lida $\mathrm{Y}$, et al. Evaluating public transit congestion mitigation measures using a passenger assignment model. Journal of the Eastern Asia Society for Transportation Studies. 2005;6:2076-2091.

[37] Kwan CM, Chang CS. Timetable synchronization of mass rapid transit system using multiobjective evolutionary approach. IEEE Transactions on Systems, Man, and Cybernetics, Part C (Applications and Reviews). 2008;38(5):636-648.

[38] Lau HCW, Chan TM, Tsui WT, et al. A fuzzy guided multi-objective evolutionary algorithm model for solving transportation problem. Expert Systems with Applications. 2009;36(4):8255-8268.

[39] Song Y, Ma J, Guan W, et al. A multi-objective model for regional bus timetable based on NSGA-II. Proceedings of the 2012 IEEE International Conference on Computer Science and Automation Engineering (CSAE); 2012 May 25-27; Zhangjiajie, China; 2012;2:185-188.

[40] Khoo HL, Teoh LE, Meng Q. A bi-objective optimization approach for exclusive bus lane selection and scheduling design. Engineering Optimization. 2014;46(7):9871007. 